International Journal of Surgery and Research (IJSR)

ISSN: 2379-156X

\title{
What is Acceptable; More Deaths Pre Transplant or More Deaths Post-Transplant. Share 35 Liver Allocation System
}

Habib S ${ }^{*}$, Khan $\mathrm{K}^{2}$

Editorial

${ }^{1}$ Department of Medicine and Surgery, Divisions of Gastroenterology, Hepatology and Liver Transplantation, Liver Research Institute, College of Medicine, University of Arizona, USA.

${ }^{2}$ Transplant Institute, MedStar Georgetown University Hospital, 3800 Reservoir Rd, Main 2, Washington, DC 20007, USA.

Keywords: Meld; Liver Transplantation; Patient Survival; Graft Survival; Intestinal Failure; Share 35 Policy.

\author{
*Corresponding Author: \\ Shahid Habib MD, \\ Arizona Health Sciences Center, University of Arizona, 1501 N Camp- \\ bell Avenue, Suite 6309, Tucson. AZ 85724, USA. \\ Tel: 520-626-5952 \\ Fax: 520-626-5975 \\ E-mail: shabib@surgery.arizona.edu
}

Received: December 30, 2014

Published: January 23, 2015

Citation: Habib S, Khan K (2015) What is Acceptable; More Deaths Pre Transplant or More Deaths Post-Transplant. Share 35 Liver Allocation System. Int J Surg Res 2(1e) 1-2. doi: http://dx.doi. org/10.19070/2379-156X-150001e

Copyright: Habib S $\mathbf{S}^{\odot}$ 2015. This is an open-access article distributed under the terms of the Creative Commons Attribution License, which permits unrestricted use, distribution and reproduction in any medium, provided the original author and source are credited.

On June 18, 2013, the organ procurement and transplant network (OPTN) implemented the, "Share-35" scheme; a change to deceased donor liver allocation. Under Share-35, all candidates in a region with a MELD (Model for End Stage Liver Disease) $\geq 35$ have priority over local candidates with MELD $<35$. This policy entails prioritization of liver transplant candidate; the sickest first. The main purpose of this allocation policy is to reduce waitlist mortality.

Since the adoption of this policy, more patients $(28 \%)$ have been transplanted at high MELD scores $(>30)$ compared to transplant recipients in or prior to 2012 or [1738 (2012 actual) vs. 2128 (2014 actual)] [1]. A preliminary analysis evaluating the impact of this policy was presented at World Transplant Congress in San Francisco, USA in the spring of 2014 [2]. Adjusting for candidate MELD, under Share-35 the liver transplant rate was $19 \%$ higher for candidates with $M E L D \geq 35(R R=1.081 .19$ $1.31, \mathrm{p}<0.001)$, with no change for candidates with lower MELD scores $(\mathrm{RR}=0.941 .001 .07, \mathrm{p}=0.9)$. The MELD-adjusted waitlist mortality decreased by $19 \%(R R=0.730 .810 .91, p<0.001)$. A recent analysis based on UNOS data revealed that with current allocation system patients with end stage liver disease were disadvantaged compared to those patients with exceptions points in particular with HCC [3].

Transplantation of high MELD patients is challenging in all respect. Among high MELD recipients, outcome is futile in about $25 \%$ of such recipients with or without transplantation resulting in wastage of organs within first year of transplantation $[4,5]$. In other words we have to lose one allograft and patient to save 3 lives. It is also evident that the majority of such patients have renal dysfunction, and creatinine $>2 \mathrm{mg} / \mathrm{dl}$ is associated with poor transplant survival regardless of the pre transplant MELD score [6]. Despite the absence of precise indication or concise criteria for simultaneous liver kidney transplantation (SLK), the number of such recipients has gone up by $10 \%$. Moreover a recent report based on UNOS data has shown that in high MELD recipients even SLK could not prevent recipient mortality [7]. This approach not only results in loss of liver allografts but also kidney allografts, which could otherwise be used for ESRD patients. The current approach might help reduce waitlist mortality but at the expense of higher post-transplant mortality. Other important post transplant issues that warrant some discussion include higher rates of renal dysfunction and SLK transplantation, higher rates of malnutrition, poor performance status, infections, increased length of stay in hospital post transplanta tion and higher cost.

The gap between the need of transplantation and availability of donor organs cannot be diminished unless some alternatives are developed. For instance It is expected that with curative treatment of $\mathrm{HCV}$ (hepatitis $\mathrm{C}$ virus), there will be a reduction in the number of patients requiring liver transplantation in the future and therefore this gap is expected to decrease. Nonetheless it is imperative to maximize utilization of the available donor pool and from an outcome perspective this would mean aiming for higher numbers of life years saved.What is therefore the goal of prioritization? Are we aiming at reducing waitlist mortality, improving post-transplant survival, improving survival benefit or maximizing resource utilization? An ideal candidate and time of transplantation should incorporate the following expected factors; lower estimated waitlist mortality, greater than $95 \%$ one year post transplant survival (expecting almost $5 \%$ surgical risk mortality), shorter length of stay in hospital, decreased rate of posttransplant complications, rapid recovery to normal functioning, no utilization of simultaneous kidney allograft and maximizing life year saved. The MELD score is good at predicting pre transplantation mortality but is not good at predicting post transplan- 
tation mortality $[4,5,8]$. Indeed there are reports indicating that the pre transplant MELD score has an inverse relationship with post-transplant survival [4,5]. Several other models have been tested to determine post transplantation survival but none has high predictive ability [9-13].

In conclusion with the current approach the risks may outweigh the benefits and a rethink of the share 35 policy is necessary. What is more acceptable, more deaths pre transplant or post-transplant? An ideal window or time for transplantation is yet to be determined; certainly the highest MELD point does not determine the ideal timing.

\section{References}

[1]. http://optn.transplant.hrsa.gov/converge/latestData/step2.asp

[2]. Massie E, Chow S Gentry, D. Segev (2014) Changes in Liver Distribution Following The Implementation of Share-35. Am J Transplant 14(S3):156190

[3]. Northup PG, Intagliata NM, Shah NL, Pelletier SJ, Berg CL, (2015).Excess mortality on the liver transplantwaiting list: Unintended policy consequences and model for End-Stage Liver Disease (MELD) inflation. Hepatology 61(1):285-91.

[4]. Habib S, Berk B, Chang CC, Demetris AJ, Fontes P (2006) MELD and Prediction of Post-Liver Transplantation Survival. Liver transplantation 12(3):440-447.

[5]. Klein KB, Stafinski TD, Menon D (2013) Predicting survival after liver transplantation based on pre-transplant MELD score: a systematic review of the literature. PLoS One 8(12):e80661

[6]. Martin EF, Huang J, Xiang Q, Klein JP, Bajaj J, et al.( 2012) Recipient survival and graft survival are not diminished by simultaneous liver-kidney transplantation: An analysis of the united network for organ sharing database. Liver Transpl 18(8):914-29.

[7]. S. Habib, E. Meister, A Rana, T Boyer (2014) Renal Dysfunction, MELD Scores, and Overall Survival of Patients With Liver (LT) Alone and Simultaneous Liver Kidney (SLK) Transplantation: A Fresh Examination of the UNOS Data. Am J Transplant 14 (S3): 156-190.

[8]. Kamath PS, Wiesner RH, Malinchoc M, Kremers W, Therneau TM, et al.(2001) A model to predict survival in patients with end-stage liver disease. Hepatology 33(2):464-470.

[9]. Rana A, Hardy MA, Halazun KJ, Woodland DC, Ratner LE, et al. (2008) Survival outcomes following liver transplantation (SOFT) score: a novel method to predict patient survival following liver transplantation. Am J Transplant 8(12):2537-2546.

[10]. Pan HC, Jenq CC, Lee WC, Tsai MH, Fan PC, et al. (2014) Scoring systems for predicting mortality after liver transplantation. PLoS One 9(9):e107138.

[11]. Bingold TM, Just L, Cuca C, Zacharowski K, Mönch C, et al.(2014) Preoperative interleukin-22 values add valuable information for outcome prediction following orthotopic liver transplantation: a preliminary study. Ann Transplant 19:503-512.

[12]. Schrem H, Reichert M, Reichert B, Becker T, Lehner F, et al.(2012) Value of the SOFA score as a predictive model for short-term survival in high-risk liver transplant recipients with a pre-transplant lab MELD score $\geq 30$.Langenbecks Arch Surg 397(5):717-726.

[13]. Sawyer RG, Durbin CG, Rosenlof LK, Pruett TL (1995) Comparison of APACHE II scoring in liver and kidney transplant recipients versus trauma and general surgical patients in a single intensive-care unit. Clin Transplant 9(5):401-405. 